\title{
Effects of osteoprotegerin/TNFRSF11B in two models of abdominal aortic aneurysms
}

\author{
EMINA VORKAPIC ${ }^{*}$, ANNE KUNATH ${ }^{*}$ and DICK WÅGSÄTER \\ Division of Drug Research, Department of Medical and Health Sciences, \\ Linköping University, 58185 Linköping, Sweden
}

Received August 14, 2017; Accepted January 26, 2018

DOI: $10.3892 / \mathrm{mmr} .2018 .8936$

\begin{abstract}
Osteoprotegerin (OPG), additionally termed tumor necrosis factor receptor superfamily member $11 \mathrm{~B}$, is produced by vascular smooth muscle cells (VSMCs) and endothelial cells in the vasculature, and its release may be modulated by pro-inflammatory cytokines, including interleukin- $1 \beta$ and tumor necrosis factor- $\alpha$. The present study investigated the effects of treatment with low-dose human recombinant OPG on abdominal aortic aneurysm (AAA) development in mice. Mice were treated with $1 \mu \mathrm{g}$ human recombinant OPG four times (or vehicle) for 2 weeks prior to inducing AAA. A total of two different models for inducing AAA were used to investigate the hypothesis as to whether OPG is involved in key events of AAA development, using osmotic mini-pumps with angiotensin II in apolipoprotein-E $\left(\mathrm{ApoE}^{-/}\right)$mice for 28 days or using periaortic application of $\mathrm{CaCl}_{2}$ on the aorta in $\mathrm{C} 57 \mathrm{Bl} / 6 \mathrm{~J}$ mice for 14 days. OPG was continuously administered during the experimental period. Histological staining using Masson's trichrome, Verhoeff's van-Gieson and picro-sirius red, in addition to reverse transcription-quantitative polymerase chain reaction analysis of various markers, were used to analyze phenotypic alterations. Treatment with OPG had no inhibitory effect on AAA development in the angiotensin II model in $\mathrm{ApoE}^{-/}$mice, which developed suprarenal aneurysms, although it increased vessel wall thickness of the aorta and total collagen in C57Bl/6J mice using the $\mathrm{CaCl}_{2}$ model that induced infrarenal dilation of the aorta. Treatment with OPG did not inhibit aneurysm development and key events, including inflammation, extracellular matrix or VSMC remodeling, in aortas from OPG-treated mice with periaortic treatment with $\mathrm{CaCl}_{2}$. The results indicated that mice treated with low levels of human recombinant OPG may
\end{abstract}

Correspondence to: Professor Dick Wågsäter, Division of Drug Research, Department of Medical and Health Sciences, Linköping University, Building 420, 58185 Linköping, Sweden

E-mail: dick.wagsater@liu.se

*Contributed equally

Key words: abdominal aortic aneurysm, collagen, remodeling, angiotensin II have a more stable aneurysmal phenotype due to compensatory production of collagen and increased vessel wall thickness of the aorta, potentially protecting the aneurysm from rupture. Further studies investigating rupture models of AAA in addition to using higher levels of OPG are require to verify this speculation. Furthermore, treatment with low levels of OPG in patients with AAA may represent a novel therapeutic strategy for the treatment of AAA as well as attenuate the adverse effects associated with the administration of normal and high dosages of OPG.

\section{Introduction}

An abdominal aortic aneurysm (AAA) is an irreversible widening of the blood vessels caused by weakening of different layers in the vascular wall. The primary complication of AAA is aortic rupture, which has an overall mortality rate of $90 \%$ (1). Currently, there is no accepted drug treatment to limit AAA rupture. The underlying mechanism of the pathogenesis of AAA remains uncertain. The pathological hallmarks of AAA are chronic inflammation, vascular smooth muscle cell (VSMC) apoptosis, extracellular matrix (ECM) degradation and thrombosis, which are additionally involved in atherosclerotic plaque formation (2). A variety of cytokines promote the destruction of the aortic wall in AAA and arteriosclerosis (3). High concentrations of the glycoprotein osteoprotegerin (OPG) have been demonstrated in human AAA biopsies $(4,5)$.

OPG, additionally termed tumor necrosis factor receptor superfamily member 11B (TNFRSF11B), is a cytokine receptor that may function as a soluble decoy receptor for the receptor activator of nuclear factor $-\kappa \mathrm{B}(\mathrm{RANK})$ and TNF-related apoptosis-inducing ligand (6-8). The RANK/RANK ligand (L)/OPG axis is involved in bone remodeling, and regulates the differentiation and activation of osteoclasts and, therefore, there is a crucial balance between bone formation and bone resorption (9). RANK is located on the surface of osteoclast precursors, including monocytes, macrophages and dendritic cells $(10,11)$. RANKL is expressed on the surface of stromal cells, osteoblasts and T cells (12). OPG functions as a soluble decoy receptor by binding to RANKL, and competitively inhibiting the interaction between RANKL and its receptor (13).

Emerging evidence has suggested that OPG is not merely a protective factor for bone, but that it may additionally act as a protective modulator in the cardiovascular system. 
Studies have reinforced the idea of OPG as a novel biomarker for cardiovascular disease (CVD) and arteriosclerosis in humans (14-16). The concentration of OPG is in fact associated with aortic diameter, and pro-inflammatory proteases and lymphocyte markers of aneurysmal disease (17).

OPG is expressed in the vascular system, including VSMCs and endothelial cells (18), and its release may be modulated by pro-inflammatory cytokines, including interleukin-1 $\beta$ (IL-1 $\beta$ ) and tumor necrosis factor- $\alpha$ (TNF- $\alpha)(19,20)$. OPG inactivation in apolipoprotein-E (ApoE)-knockout mice accelerates advanced atherosclerotic lesion progression and vascular calcification (21), which is in accordance with an earlier study that reported profound calcification of the large arteries, including intimal and medial proliferation, in mice with targeted disruption of OPG (22). In line with these findings, transgenic expression of OPG prevented the formation of calcified lesions in the arteries of adolescent mice (23). Furthermore, high levels of OPG were demonstrated to promote the accumulation of VSMCs and the formation of collagen, although it did not affect the inflammatory properties of atherosclerotic lesions (24). In a study by Candido et al (25), low levels of OPG ( $1 \mu \mathrm{g}$ every $3 \mathrm{rd}$ week) increased the number of VSMCs in aortic plaques.

A total of two independent studies have investigated the effects of OPG and AAA in mice. Moran et al (26) used ApoE/OPG double knockouts with angiotensin II (angII)-induced AAA that resulted in a reduction in pro-inflammatory markers and an inhibition of aortic dilation and rupture. By contrast, results by Bumdelger et al (27) demonstrated that OPG-knockout in mice using a $\mathrm{CaCl}_{2}$-induced AAA model promoted AAA formation.

The impact of treatment with OPG in the development of CVD and AAA remains unclear. Based on the previous findings, the present study hypothesized that OPG may be involved in key events of AAA development, including stabilization of the vessel wall through compensatory production of collagen.

In the present study, two different functional mouse models of AAA were used with the aim of assessing the effects of low levels of OPG in AAA development in mice.

\section{Material and methods}

Mouse experiments. All mouse experiments were approved by Stockholm North Ethical Committee on Animal Research (Stockholm, Sweden). Mice were treated with the analgesic buprenorphine (Temgesic; $0.1 \mathrm{mg} / \mathrm{kg}$; Indivior UK Limited, Slough, UK) two times per day for $72 \mathrm{~h}$ following surgery. Operated animals were inspected every day for any sign of pain or disability. No abnormal behaviour indicating pain or distress, or surgical site infection was observed in any of the mice after surgery during the study. If any animals would suffer from the above they would be sacrificed. However, this was never needed. Mice ( $n=64$; male; weighing 20-30 g) were fed a normal chow diet and water was provided ad libitum during the whole observation period. Animals were housed in a controlled temperature of $22^{\circ} \mathrm{C}$, a $12 / 12 \mathrm{~h}$ light/dark cycle and a humidity of 40-60\%. For histology and gene expression analysis, the aortas of the mice were removed and immediately fixed in either $4 \%$ zinc formaldehyde at room temperature for $24 \mathrm{~h}$ or in RNAlater (Ambion; Thermo Fisher Scientific, Inc.,
Waltham, MA, USA) at $4^{\circ} \mathrm{C}$ for $24 \mathrm{~h}$, and subsequently frozen at $-70^{\circ} \mathrm{C}$.

AngII-induced AAA in mice. A total of 2 weeks prior to the induction of AAA using angII, mice were randomized to be administered injections of recombinant human (rh)-OPG (1 $\mu \mathrm{g}$ twice a week; R\&D Systems, Inc., Minneapolis, MN, USA) or $0.9 \% \mathrm{NaCl}$ intraperitoneally during the two weeks. In eight week-old male $\mathrm{ApoE}^{-/-}$mice (Taconic Biosciences, Bomholt, Denmark), AAA was induced by chronic infusion of 1,000 ng/kg/min angII (cat no. 9525; Sigma-Aldrich; Merck KGaA, Darmstadt, Germany) or $0.9 \% \mathrm{NaCl}$ as a control via mini-osmotic pumps (Model 1004; Alzet, Cupertino, CA, USA). Mice were anesthetized with $2 \%$ isoflurane and $0.5 \mathrm{l} / \mathrm{min}$ oxygen through a nose mask. The pumps were implanted subcutaneously into the right flank of the mice to release angII over a period of 28 days. Rh-OPG was loaded into the mini-osmotic pumps for additional continuous administration of $7.1 \mu \mathrm{g}$ OPG during the 28 days of the experiment. Groups were divided as follows: $\mathrm{NaCl}$ and $\mathrm{NaCl}(\mathrm{n}=5)$, angII and $\mathrm{NaCl}(\mathrm{n}=9), \mathrm{NaCl}$ and rh-OPG $(\mathrm{n}=7)$, and angII and rh-OPG $(\mathrm{n}=10)$.

$\mathrm{CaCl}_{2}$-induced AAA in mice. $\mathrm{C} 57 \mathrm{Bl} / 6 \mathrm{~J}$ mice of 8 weeks of age, purchased from Jackson Laboratory (Bar Harbor, ME, USA), were anesthetized with $2 \%$ isoflurane and $0.5 \mathrm{l} / \mathrm{min}$ oxygen through a nose mask, and were randomized to receive rh-OPG and periaortic application of $\mathrm{CaCl}_{2}$. A small compress strip soaked with $0.5 \mathrm{M} \mathrm{CaCl}_{2}$ or saline as a control was applied to the isolated abdominal aorta, which was covered for $15 \mathrm{~min}$. Thereafter, the compress was removed, and the treated area was dried and washed twice with saline. At 2 weeks, the mice were sacrificed. Three groups were divided as follows: $\mathrm{CaCl}_{2}$ and saline $(\mathrm{n}=10), \mathrm{CaCl}_{2}$ and rh-OPG $(\mathrm{n}=10)$, saline and saline $(\mathrm{n}=10)$. The intraperitoneal $\mathrm{rh}-\mathrm{OPG}(1 \mu \mathrm{g}$ twice a week; R\&D Systems) or saline treatment was administrated four times before and four times following surgery to induce aneurysm using the $\mathrm{CaCl}_{2}$-model (two injections/week). On the day of surgery, the mice received an rh-OPG/vehicle injection. In total, the mice had nine intraperitoneal injections of rh-OPG/vehicle during the 4 weeks.

Measurement of mouse abdominal aortic diameter. Following dehydration, paraffin embedding and sectioning (5 $\mu \mathrm{m}$ ), aortas were incubated in Bouin's solution (Sigma Aldrich; Merck KGaA) overnight at room temperature, counterstained with Weigert's hematoxylin (HistoRx, New Haven, CT, USA) for $10 \mathrm{~min}$ at room temperature and stained with the Masson's Trichrome kit (Sigma Aldrich; Merck KGaA), according to the manufacturer's protocol (phosphomolybdic acid fuchsin solution for $10 \mathrm{~min}$; aniline blue for $5 \mathrm{~min}$ ) at room temperature. Whole sections were observed under a light microscope (magnification, x10 and x40). Aortic circumference was measured for the outer adventitial area and for the inner luminal area. The vessel wall thickness was determined from the outer adventitial diameter and the inner luminal diameter. Definition of an aneurysm was set as a 1.5-fold enlargement of the aortic wall. To measure aortic outer diameter, the largest part of the aorta was taken for this purpose. 
Quantification of collagen and elastin. Aortic sections were stained with Picro-sirius red (Sigma Aldrich; Merck KGaA) for $1 \mathrm{~h}$ at room temperature to visualize thin and thick collagen fibers and washed with $1 \%$ acetic acid twice for $10 \mathrm{~min}$ at room temperature. Measurements were made using the LeicaQWin image analysis software (Leica Microsystems GmbH, Wetzlar, Germany) to measure the amount of red-orange and yellow-green color relative to the aortic area. Thick collagen fibers presented an intense birefringence resulting in a red-orange color, whereas thin collagen fibers presented a weak birefringence with a yellow-green color when observing through a light microscope under polarized light (magnification, x10 and x40).

For elastin, paraffin embedded abdominal aortic sections $(5 \mu \mathrm{m})$ were stained with Verhoeff's hematoxylin for $1 \mathrm{~h}$, differentiated in $2 \%$ ferric chloride for $2 \mathrm{~min}$ and counterstained with Van Gieson solution for $5 \mathrm{~min}$ (all at room temperature) to identify elastic fibers in the aortic tissue. For analysis, a scoring system between 1 and 4 was used, and a score of 1 was defined as intact elastin, a score of 2 as low elastin degradation, a score of 3 as intermediate elastin degradation and a score of 4 as high elastin degradation.

Cell culture of human aortic smooth muscle cells. Human vascular aortic SMCs, obtained from the American Type Culture Collection (Manassas, VA, USA), were maintained in smooth muscle growth medium-2 containing $5 \%$ fetal bovine serum (FBS; CC-3182; Clonetics; Cambrex Bio Science Walkersville, Inc.; Lonza Group Ltd., Basel, Switzerland). The cells were used at passages 3-5. All cells were incubated in $5 \% \mathrm{CO}_{2}$ at $37^{\circ} \mathrm{C}$ and stimulated with $20 \mathrm{ng} / \mathrm{ml}$ recombinant TNF- $\alpha, 20 \mathrm{ng} / \mathrm{ml}$ interferon- $\gamma($ IFN- $\gamma$ ) or $10 \mathrm{ng} / \mathrm{ml} \mathrm{IL-1 \beta}$ (R\&D Systems) for 4,24 and $48 \mathrm{~h}$ at $37^{\circ} \mathrm{C}$.

Reverse transcription-quantitative polymerase chain reaction $(P C R)$. Total RNA was extracted from aortas and VSMCs using TRIzol (Thermo Fisher Scientific, Inc.) and an RNeasy Mini kit (Qiagen GmbH, Hilden, Germany). RNA was reverse transcribed with random primers and Superscript III, according to the manufacturer's protocol (cat. nos. 48190-011, 18427-013 and 18080093; Invitrogen; Thermo Fisher Scientific, Inc.). Briefly, total RNA, primers and dNTPs were heated to $65^{\circ} \mathrm{C}$ for $5 \mathrm{~min}$, incubated on ice for $1 \mathrm{~min}$ and then mixed with first strand buffer, dithiothreitol and Superscript III, and then further incubated at $50^{\circ} \mathrm{C}$ for $30 \mathrm{~min}$. Following this, the reaction was inactivated via incubation at $70^{\circ} \mathrm{C}$ for $15 \mathrm{~min}$. From each PCR product, using the standard curve method in a fluorescent temperature cycler, cDNA (1.0 ng) was amplified for 40 cycles (denaturation at $95^{\circ} \mathrm{C}$ for $3 \mathrm{sec}$ and extension at $60^{\circ} \mathrm{C}$ for $30 \mathrm{sec}$ ) in a $20 \mu \mathrm{l}$ PCR reaction volume using the TaqMan Universal PCR Mastermix (Applied Biosystems; Thermo Fisher Scientific, Inc.) in 96-well fast plates on a 7500 Fast Real-time PCR Sequence Detector (Applied Biosystems; Thermo Fisher Scientific, Inc.) in duplicate. The following gene expression assays, all purchased from Applied Biosystems; Thermo Fisher Scientific, Inc., were used: Adiponectin (cat no. Mm00456425_m1); integrin subunit $\alpha \mathrm{M}$ (CD11b; cat no. Mm00434455_m1); CD68 (cat no. Mm03047340_m1); cathepsin K (cat no. Mm00484036_m1); cathepsin S (cat no. Mm00457902_m1); TNF- $\alpha$ (cat no. Mm00443258_ $\mathrm{m} 1) ; \alpha$-actin (cat no. Mm1187533_m1); transgelin (Sm22 $\alpha$; cat no. Mm00441660_m1); lysyl oxidase (Lox; cat no. Mm01265612) and OPG (cat no. Hs00900358_m1). The results were normalized to the values of murine TATA-box bindingprotein(catno.Mm00446973_m1)orhumanribosomal protein lateral stalk subunit P0 (cat no. Hs00420895_gH).

Measurement of OPG from VSMCs. Secreted levels of OPG were measured in the muscle growth medium-2 containing $5 \%$ FBS from cultured VSMCs from three separate experiments that had been cultured for $48 \mathrm{~h}$ prior to analysis using an ELISA kit, according to the manufacturer's protocol (cat no. DY805; human OPG; R\&D Systems, Inc.).

Statistical analysis. Statistical analyses were performed using SPSS software version 24 (IBM Corp., Armonk, NY, USA) and GraphPad Prism version 7 software (GraphPad Software, Inc., La Jolla, CA, USA). Data are presented as the mean \pm standard deviation. Differences between groups were analyzed by two-tailed unpaired t-test and one way analysis of variance followed by the Bonferroni method post hoc test. $\mathrm{P}<0.05$ was considered to indicate a statistically significant difference.

\section{Results}

Minor effects of treatment with OPG in angII-induced AAA development. Infusion of angII induced AAA in eight out of nine vehicle control and nine out of ten OPG-treated mice. Sections were not available for aortic investigation in three mice of the vehicle and one mouse of the OPG-treated mice. In total, one mouse succumbed to rupture in the vehicle-treated angII group and one in the OPG-treated angII group. Treatment with OPG in angII infused mice had no significant effect on luminal diameter (Fig. 1A), outer diameter of the aorta (Fig. 1B) or vessel wall thickness (Fig. 1C) compared with angII-infused saline treated mice. Treatment with OPG led to significantly increased aortic diameter in $\mathrm{ApoE}^{-/}$control mice that were treated with saline instead of angII, although this did not remain significant after adjustment for multiple comparison (data not shown). Treatment with OPG in control mice did not markedly alter the diameter of the lumen or vessel wall thickness (Fig. 1A and C) compared with control mice treated with saline. Both angII-infused groups of mice (angII+NaCl and angII+OPG) exhibited significantly increased degradation of elastin compared with their control littermates that were not treated with angII, and treatment with OPG did not contribute to any alterations in elastin degradation as indicated by Verhoeff's van Gieson staining (Fig. 1D and upper panel of Fig. 2). No differences were observed in the amount of collagen between OPG-treated and untreated mice as indicated by Masson trichrome staining (Fig. 2).

Treatment with OPG increases vessel wall thickness and collagen levels in the aorta in $\mathrm{CaCl}_{2}$-induced dilated aortas. Periaortic application of $\mathrm{CaCl}_{2}$ resulted in a small, although significant, dilatation of the aorta compared with the control (Fig. 3A). No animals succumbed to rupture (data not shown). Furthermore, treatment with OPG led to 

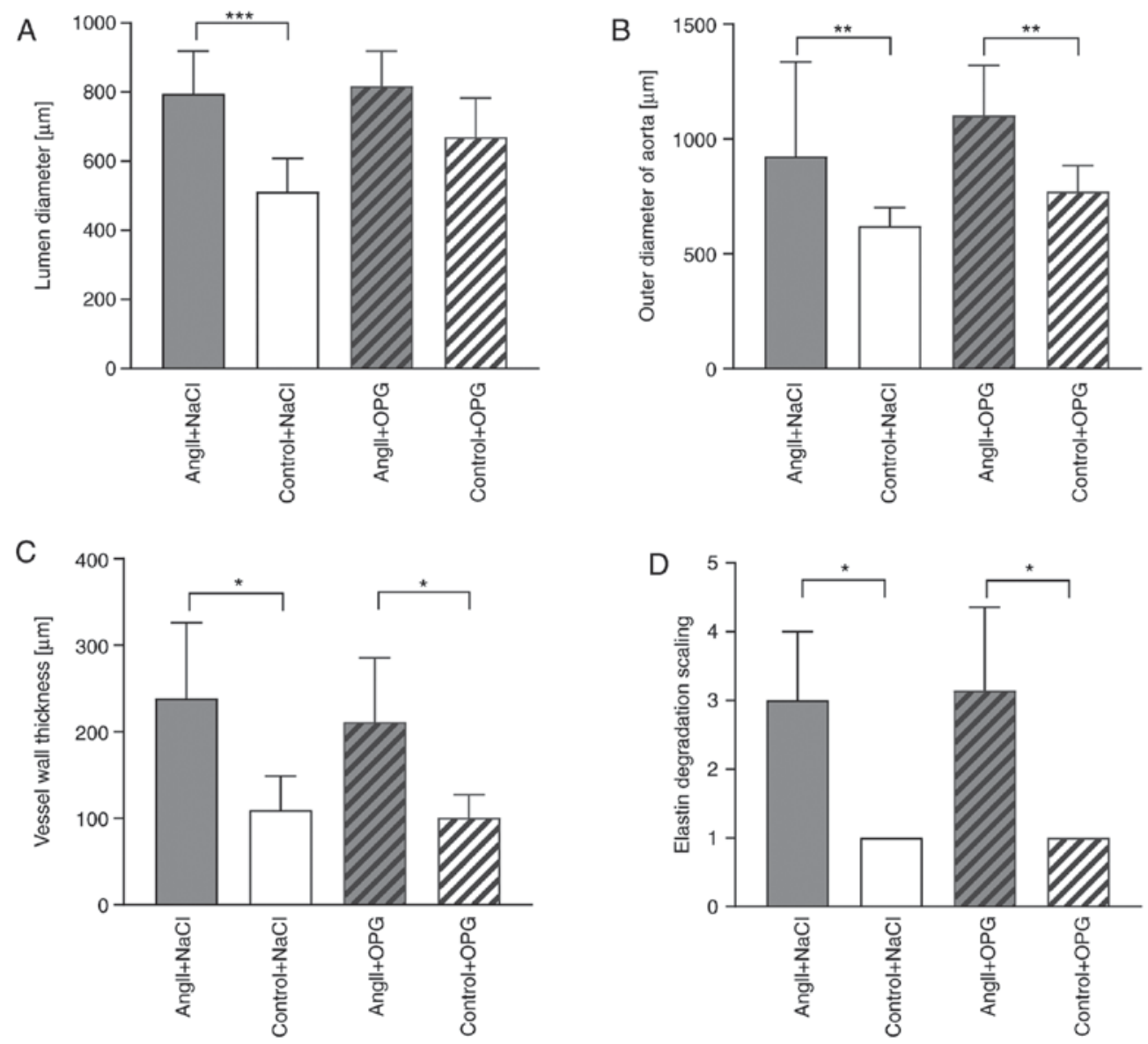

Figure 1. Effects of $\mathrm{OPG}$ using the angII model in $\mathrm{ApoE}^{-/}$mice. (A) Lumen diameter, (B) outer aortic diameter and (C) vessel wall thickness in saline-treated mice $(\mathrm{n}=5)$, angII-treated $\mathrm{ApoE}^{-/}$mice $(\mathrm{n}=8)$, saline-treated $\mathrm{ApoE}^{-/}$mice with $\mathrm{OPG}(\mathrm{n}=7)$ and angII-treated $\mathrm{ApoE}^{-/}$mice with OPG $(\mathrm{n}=9)$. (D) Elastin degradation, for which a score of 1 was defined as intact elastin and a score of 3 as intermediate elastin degradation. ${ }^{*} \mathrm{P}<0.05,{ }^{* * *} \mathrm{P}<0.01,{ }^{* * * *} \mathrm{P}<0.001$. OPG, osteoprotegerin; ApoE, apolipoprotein-E; angII, angiotensin II.

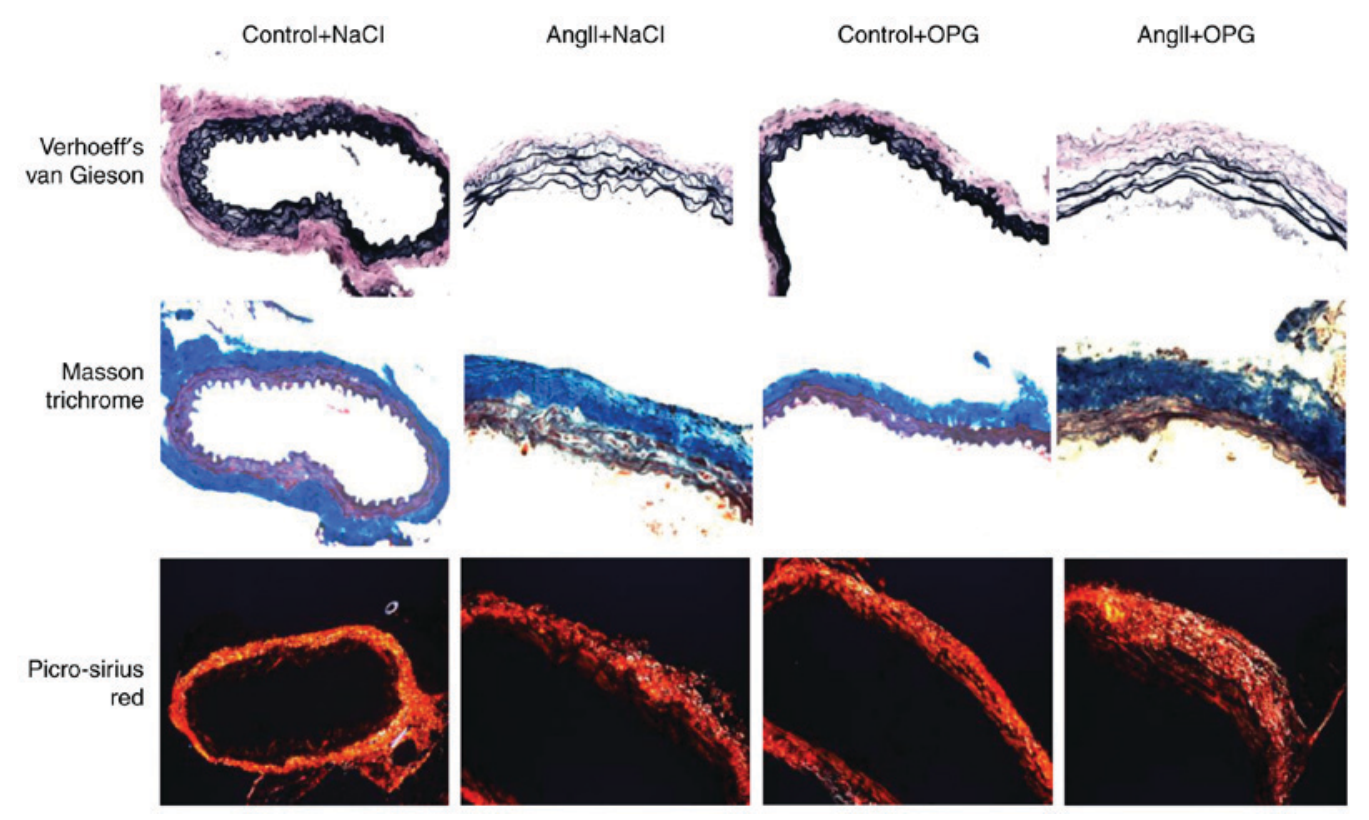

Figure 2. Representative histology staining in $\mathrm{ApoE}^{-/}$mice. Verhoeff's-van Gieson staining of elastin. Masson's trichrome staining of collagen. Picro-sirius red staining of collagen. OPG, osteoprotegerin; AngII, angiotensin II (magnification, x10).

significantly increased vessel wall thickness of the aorta in the $\mathrm{CaCl}_{2}$-induced AAA mice compared with control mice
(Fig. 3B); however, this did not remain significant after adjustment of multiple comparison. Total collagen composition, 

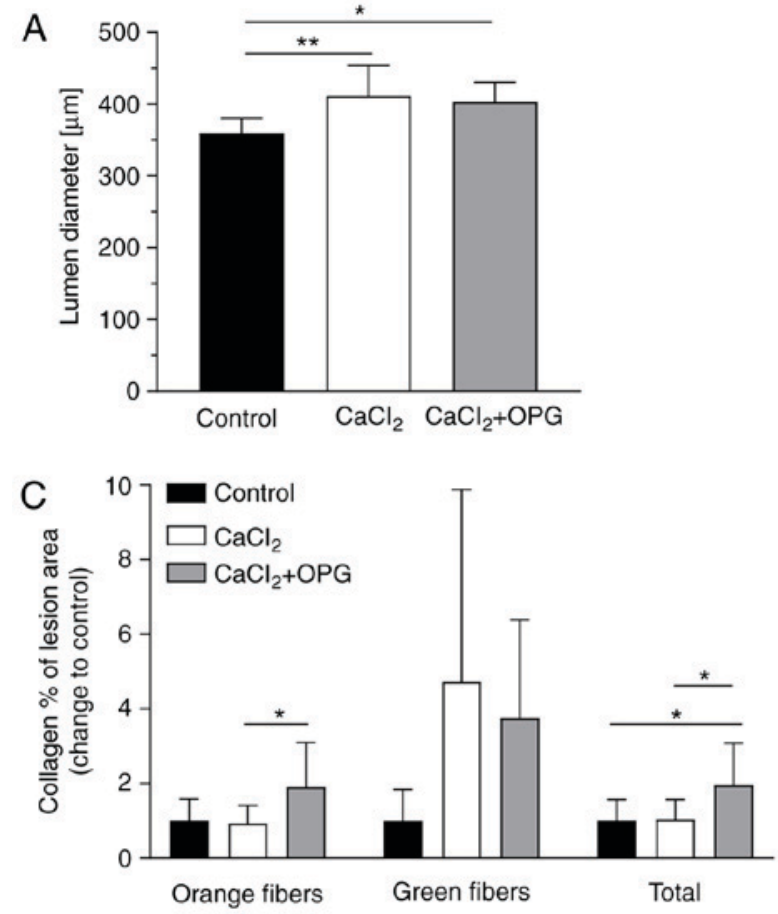
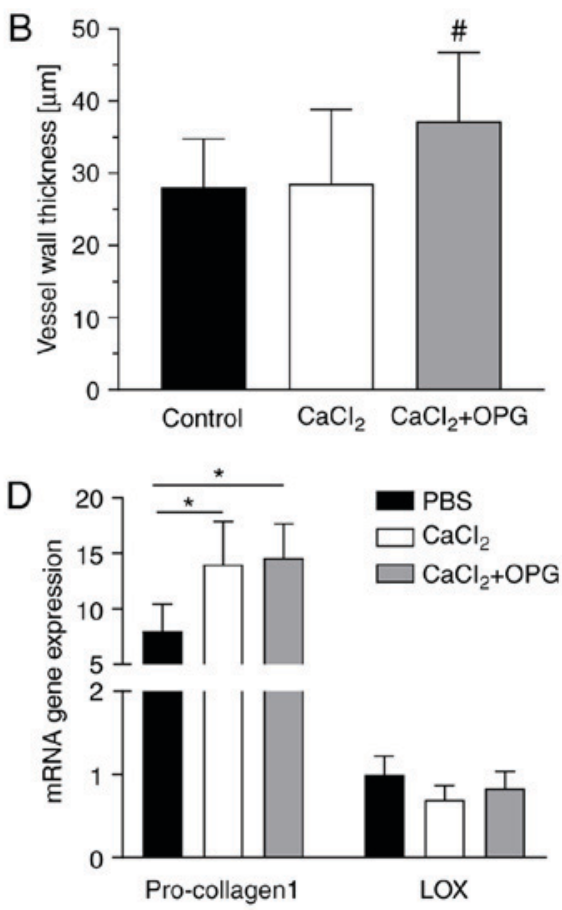
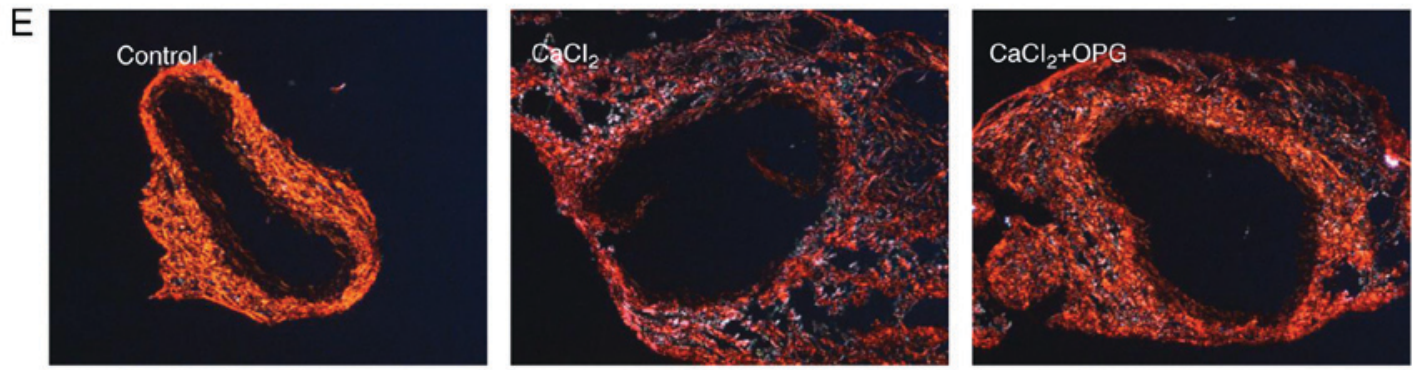

Figure 3. Effects of OPG using the $\mathrm{CaCl}_{2}$ model in $\mathrm{C} 57 \mathrm{Bl} / 6$ mice. (A) Luminal diameter and (B) vessel wall thickness of the aorta in saline-treated aortas $(\mathrm{n}=10), \mathrm{CaCl}_{2}$-treated aortas $(\mathrm{n}=10)$ and $\mathrm{CaCl}_{2}$-treated aortas with rh-OPG $(\mathrm{n}=9)$. (C) Collagen composition in lesions of the aorta. These data illustrate area of orange (thick collagen fibers), green (thin collagen fibers) and the total stained area, and are presented as the fold-change compared with control mice. (D) Reverse transcription-quantitative polymerase chain reaction analysis of collagen in aortic extracts of saline-treated mice, CaCl ${ }_{2}$-treated mice and $\mathrm{CaCl}_{2}$-treated mice with OPG. (E) Representative picro-sirius red staining of a normal saline-treated mouse aorta and aneurysmal CaCl ${ }_{2}$-treated mouse aorta with and without treatment with OPG (magnification, $\mathrm{x} 10$ ). ${ }^{*} \mathrm{P}<0.05 ;{ }^{* *} \mathrm{P}<0.01 .{ }^{*} \mathrm{P}<0.05$ vs. control when using the Student's t-test. Statistical comparisons between groups are indicated by the start and end of the bars. OPG, osteoprotegerin; rh, recombinant human.

primarily accounted for by mature fibers, was twice as high throughout the lesions in the aorta of OPG-treated mice compared with vehicle-treated controls and $\mathrm{CaCl}_{2}$-induced mice (Fig. 3C). At the mRNA level, pro-collagen1 expression was significantly increased in AAA-developing mice compared with controls, although there was no significant difference in OPG-treated mice (Fig. 3D). Treatment with OPG exerted no effect on Lox expression (Fig. 3D). Fig. 3E demonstrates that collagen composition was higher in lesions of OPG-treated mice compared with control mice. There were no detectable differences in elastin degradation in mice following treatment with OPG (data not shown).

Low levels of OPG do not affect inflammatory and ECM gene expression in the abdominal aortic wall of $\mathrm{CaCl}_{2}$-treated aortas. Significantly increased mRNA expression levels of markers of inflammation, including (TNF- $\alpha$ ), macrophages (Cd68), leukocytes (Cd11b), adipokines (adiponectin) and proteases (cathepsin $\mathrm{K}$ and cathepsin $\mathrm{S}$ ) was observed, and a significant reduction in the mRNA expression levels of VSMC markers $(\alpha$-actin and Sm-22 $\alpha)$ in the mice with periaortic $\mathrm{CaCl}_{2}$ application compared with their littermate controls (Fig. 4). However, treatment with OPG did not affect the mRNA expression of the genes compared with $\mathrm{CaCl}_{2}$ mice without OPG injection (Fig. 4). An exception was observed in the expression of adiponectin, which was not increased in the $\mathrm{CaCl}_{2}$-treated mice administered OPG compared with the control group.

Cytokines cause altered OPG expression in human aortic VSMCs. As VSMCs are primary components of the aortic wall and are important producers of OPG, the regulatory effects of different cytokines on OPG expression were analyzed in the media from human aortic VSMCs in vitro. Stimulation of cultured human aortic VSMCs with TNF- $\alpha$ and IL-1 $\beta$ led to a 2-3 fold higher release of OPG, respectively, whereas IFN- $\gamma$ downregulated the levels of OPG following $48 \mathrm{~h}$ of stimulation compared with the control group (Fig. 5). Similar results were observed at $24 \mathrm{~h}$ of stimulation, whereas $4 \mathrm{~h}$ of stimulation did not lead to any significant release (data not shown). 


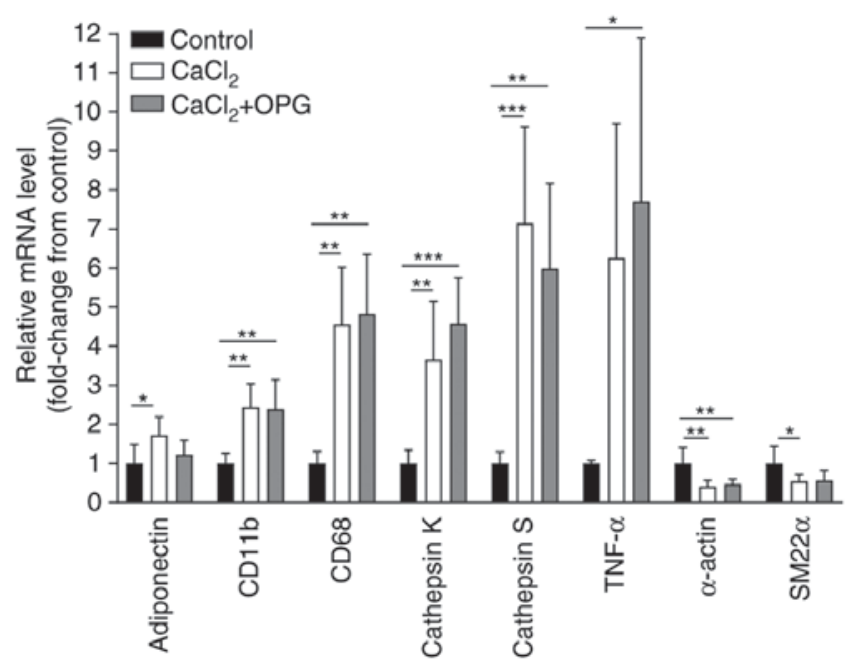

Figure 4. Gene expression levels in the aortas of mice. Reverse transcription-quantitative polymerase chain reaction analysis of genes in aortic extracts of saline treated control mice $(n=4), \mathrm{CaCl}_{2}$-treated mice $(\mathrm{n}=7)$ and $\mathrm{CaCl}_{2}$-treated mice with OPG $(\mathrm{n}=7)$. mRNA expression levels were normalized to those of TATA-box binding protein and are presented as a fold-change compared with control mice. ${ }^{*} \mathrm{P}<0.05 ;{ }^{* *} \mathrm{P}<0.01 ;{ }^{* * *} \mathrm{P}<0.001$ Statistical comparisons between groups are indicated by the start and end of the bars. OPG, osteoprotegerin; CD11b, integrin subunit $\alpha \mathrm{M}$; TNF- $\alpha$, tumor necrosis factor- $\alpha$; SM22 $\alpha$, transgelin.

\section{Discussion}

The present study investigated the role of low-dose treatment with $\mathrm{OPG}$ in the development of $\mathrm{CaCl}_{2}$ - and angII-induced AAA. There has been increased interest in the role of OPG as a predictor of CVD. Growing evidence has suggested that circulating levels of OPG may serve as potential markers of CVD and AAA risk; however, the role of this protein in the arterial wall in relation to AAA remains unclear.

The present study focused on OPG, a glycoprotein that serves as a decoy receptor with suggested protective properties in the cardiovascular system. First, the present study used the angII-induced AAA model on $\mathrm{ApoE}^{-/-}$background mice to investigate the role of human rh-OPG in AAA development. However, treatment with low levels of human rh-OPG did not alter the progression of AAA in these mice. Bennett et al (21) reported a protective role of OPG via its inactivation in $\mathrm{ApoE}^{-/-}$mice that accelerated advanced atherosclerotic lesion progression and vascular calcification. These findings suggested that endogenous OPG acts as an inhibitor of atherogenesis, whereas exogenous OPG did not contribute to an improvement of advanced AAA development in the $\mathrm{ApoE}^{-/-}$mouse model in the present study. This result was confirmed by Morony et al (28), who concluded that high levels of exogenously injected OPG did not alter the amount of atherosclerosis in $\mathrm{ApoE}^{-/-}$mice. Candido et al (25) demonstrated that low-dose treatment with rh-OPG (1 $\mu \mathrm{g}$ injection every 3 weeks) resulted in a slight increase in total aortic plaque area in diabetic $\mathrm{ApoE}^{-/}$mice with a significant increase in VSMC content. Despite very low levels of rh-OPG, these researchers were able to detect rh-OPG in the serum of treated animals at 1 and 7 days post-administration. In the experiments of the present study, a similar approach was used by administering low levels of OPG (1 $\mu \mathrm{g}$ twice a week) and, consistent with Candido et al (25), the present study

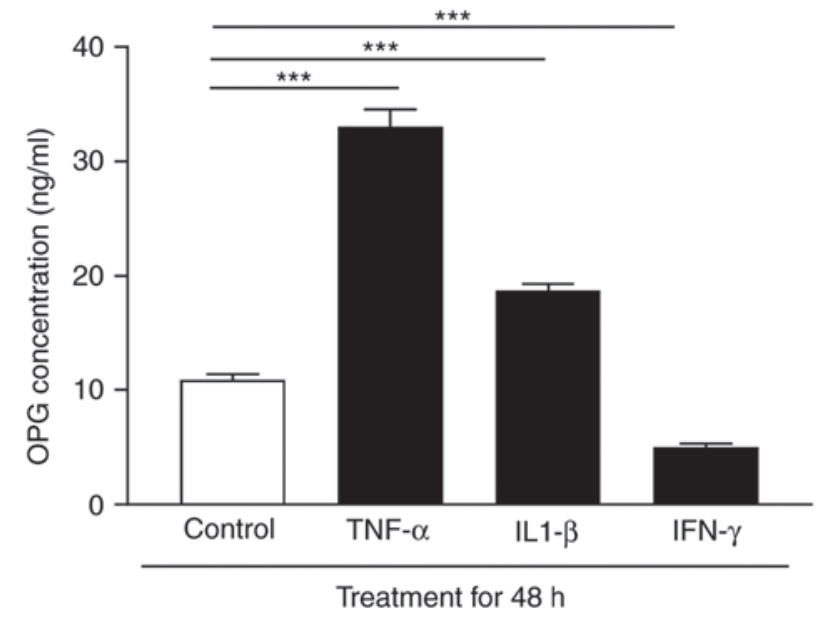

Figure 5. Release of OPG from VSMCs. OPG concentration (ng/ml) following $48 \mathrm{~h}$ of treatment with saline, TNF- $\alpha$, IL1- $\beta$ and IFN- $\gamma$ in human VSMCs. Experiments were repeated thrice. ${ }^{* * *} \mathrm{P}<0.001$. Statistical comparisons between groups are indicated by the start and end of the bars. OPG, osteoprotegerin; TNF- $\alpha$, tumor necrosis factor- $\alpha$; IL1- $\beta$, interleukin $1 \beta$; IFN- $\gamma$, interferon- $\gamma$; VSMCs, vascular smooth muscle cells.

detected levels of rh-OPG in the serum of mice, despite the levels being very low (data not shown). Differences in the results of previous studies may be reflected in the dosage and administration time of OPG, fusion or native OPG, in addition to the age and strain of animals used in the experiments. However, a study by Moran et al (26) using ApoE/OPG double knockouts with the angII-induced AAA model resulted in an inhibition of aortic dilation and rupture. A total of $30 \%$ of angII-induced animals used in the Moran et al (26) study developed rupture, which was greater than the $9 \%$ of angII-induced animals that developed ruptures in the present study. One may speculate upon whether this result was atherosclerosis-dependent as 6 month-old mice were used, however, similar results were obtained in $\mathrm{C} 57 \mathrm{Bl} / 6$ background mice, thus suggesting that older animals are more prone to developing ruptures.

To investigate method-specific effects of exogenous administered rh-OPG, the present study used $\mathrm{CaCl}_{2}$ to induce AAA in $\mathrm{C} 57 \mathrm{Bl} / 6 \mathrm{~J}$ mice. The differences in the pathogenesis of AAA between the $\mathrm{CaCl}_{2}$ and angII models were marked. AngII-induced AAA are located in the suprarenal areas and may develop a thrombus, while $\mathrm{CaCl}_{2}$-induced AAA appear in the infrarenal aorta with no thrombus formation, among other differences. Composition of collagen and elastin vary in the suprarenal and infrarenal parts of the aorta. In the present study, the effects of $\mathrm{CaCl}_{2}$ on aneurysmal development were smaller compared with the angII model, usually causing only dilation of the aorta. However, this may be beneficial, as dilation is developed prior to an aneurysm and is difficult to study in models causing large aneurysms. In addition, with respect to the studies performed by Moran and Bumdelger (26,27), OPG knockout led to AAA inhibition in angII/ApoE and augmentation of $\mathrm{AAA}$ in $\mathrm{CaCl}_{2} / \mathrm{C} 57 \mathrm{bl} / 6$ model mice.

In the present study, a significant increase in the vessel wall thickness through treatment with OPG was observed when using the $\mathrm{CaCl}_{2}$ model. This may be contradictory to the finding of Bucay et al (22) that $\mathrm{OPG}^{-/-}$mice develop profound calcification of large arteries, including intimal 
and medial proliferation. The results may be explainable by a compensatory increase in the production of collagen in OPG-treated mice, although treatment with OPG exerted no influence on pro-collagen 1 or Lox expression, which may contribute to collagen fiber formation (29). Enhanced plaque stability through collagen accumulation was promoted by chronic treatment with OPG (24), and this supports the hypothesis of the present study that a more stable aneurysmal phenotype leads to increased collagen content. Furthermore, one may speculate as to whether increased vessel wall thickness depends on increased VSMC content due to increased proliferation and/or decreased apoptosis, or a in phenotypic switch. There were no observed effects on inflammation, the ECM or VSMC remodeling in aortas from the mice treated with OPG in the present study. A reason for this may potentially be explained by the low dosage of OPG used in the present study. However, these observations were partially in agreement with the results from Ovchinnikova et al (24), who reported a promotion of SMC accumulation, although no influence on inflammation with chronic treatment with OPG when using a high dosage of OPG. The lack of effect of OPG on inflammation in the present study is in accordance with a report that subcutaneous injections of human rh-OPG for 5 months led to decreased atherosclerotic calcified lesions in $\mathrm{LDLR}^{-/-}$mice, although they did not affect the total burden of atherosclerotic lesions (28).

OPG is produced and secreted by VSMCs (18), in which it inhibits vascular calcification (30). With regard to the finding that high circulating OPG levels are associated with the extent of CVD, the present study examined the effects of pro-inflammatory cytokines on OPG secretion from human VSMCs to investigate the possible regulatory effects of OPG. It is known that rh-OPG promotes the proliferation of SMCs in both human and rodent cells $(9,25)$ and that OPG may be modulated by pro-inflammatory cytokines $(19,20)$. The results of the present study demonstrated that stimulation of cultured human aortic SMCs with TNF- $\alpha$ and IL-1 $\beta$ led to a 3 -fold or doubled increase in the release of OPG, whereas IFN- $\gamma$ addition significantly decreased OPG expression in human aortic SMCs by one-half. Earlier in vitro studies demonstrated that the expression and release of OPG was markedly upregulated in VSMCs in response to inflammatory cytokines, including TNF- $\alpha$ and IL1- $\beta(31,32)$.

In conclusion, the results of the present study indicated that C57Bl/6 mice treated with human rh-OPG have an increased vessel wall thickness and collagen content. This suggested a potential protective effect against dangerous rupture in advanced AAA development. However, the present study did not observe any ruptures using the $\mathrm{CaCl}_{2}$ model and, therefore, this remains speculation. Although rupture occurred in the angII model, many more animals than those included in the present study would be required in each group to obtain any differences with enough power. Further studies investigating rupture models of AAA and using higher levels of OPG are required to verify whether OPG exhibits any protective effects against aneurysm rupture.

\section{Acknowledgements}

Not applicable.

\section{Funding}

No funding was received.

\section{Availability of data and materials}

All data generated or analysed during this study are included in this published article.

\section{Authors' contributions}

EV and DW contributed to concept and design of the study. EV and DW performed experiments. EV, AK and DW analyzed the data and contributed to the writing and revision of the manuscript, as well as approving the final manuscript.

\section{Ethics approval and consent to participate}

All mouse experiments were approved by Stockholm North Ethical Committee on Animal Research (Stockholm, Sweden).

\section{Consent for publication}

Not applicable.

\section{Competing interests}

The authors declare that they have no competing interests.

\section{References}

1. Assar AN and Zarins CK: Ruptured abdominal aortic aneurysm: A surgical emergency with many clinical presentations. Postgrad Med J 85: 268-273, 2009.

2. Toghill BJ, Saratzis A and Bown MJ: Abdominal aortic aneurysm-an independent disease to atherosclerosis? Cardiovasc Pathol 27: 71-75, 2017.

3. Shimizu K, Libby P and Mitchell RN: Local cytokine environments drive aneurysm formation in allografted aortas. Trends Cardiovasc Med 15: 142-148, 2005.

4. Moran CS, McCann M, Karan M, Norman P, Ketheesan N and Golledge J: Association of osteoprotegerin with human abdominal aortic aneurysm progression. Circulation 111: 3119-3125, 2005.

5. Moran CS, Clancy P, Biros E, Blanco-Martin B, McCaskie P, Palmer LJ, Coomans D, Norman PE and Golledge J: Association of PPARgamma allelic variation, osteoprotegerin and abdominal aortic aneurysm. Clin Endocrinol (Oxf) 72: 128-132, 2010.

6. Emery JG, McDonnell P, Burke MB, Deen KC,Lyn S, Silverman C, Dul E, Appelbaum ER, Eichman C, DiPrinzio R, et al: Osteoprotegerin is a receptor for the cytotoxic ligand TRAIL. J Biol Chem 273: 14363-14367, 1998.

7. Simonet WS, Lacey DL, Dunstan CR, Kelley M, Chang MS, Lüthy R, Nguyen HQ, Wooden S, Bennett L, Boone T, et al: Osteoprotegerin: A novel secreted protein involved in the regulation of bone density. Cell 89: 309-319, 1997.

8. Pan G: An antagonist decoy receptor and a death domain-containing receptor for TRAIL. Science 277: 815-818, 1997.

9. Pérez de Ciriza C, Lawrie A and Varo N: Osteoprotegerin in cardiometabolic disorders. Int J Endocrinol 2015: 564934, 2015.

10. Lacey DL, Timms E, Tan HL, Kelley MJ, Dunstan CR, Burgess T, Elliott R, Colombero A, Elliott G, Scully S, et al: Osteoprotegerin ligand is a cytokine that regulates osteoclast differentiation and activation. Cell 93: 165-176, 1998.

11. Hofbauer LC and Schoppet M: Clinical implications of the osteoprotegerin/RANKL/RANK system for bone and vascular diseases. JAMA 292: 490-495, 2004. 
12. Kong YY, Yoshida H, Sarosi I, Tan HL, Timms E, Capparelli C, Morony S, Oliveira-dos-Santos AJ, Van G, Itie A, et al: OPGL is a key regulator of osteoclastogenesis, lymphocyte development and lymph-node organogenesis. Nature 397: 315-323, 1999.

13. Hofbauer LC, Shui C, Riggs BL, Dunstan CR, Spelsberg TC, O'Brien T and Khosla S: Effects of immunosuppressants on receptor activator of NF-kappaB ligand and osteoprotegerin production by human osteoblastic and coronary artery smooth muscle cells. Biochem Biophys Res Commun 280: 334-339, 2001.

14. Lieb W, Gona P, Larson MG, Massaro JM, Lipinska I, Keaney JF Jr, Rong J, Corey D, Hoffmann U, Fox CS, et al: Biomarkers of the osteoprotegerin pathway: Clinical correlates, subclinical disease, incident cardiovascular disease, and mortality. Arterioscler Thromb Vasc Biol 30: 1849-1854, 2010.

15. Abedin M, Omland T, Ueland T, Khera A, Aukrust P, Murphy SA, Jain T, Gruntmanis U, McGuire DK and de Lemos JA: Relation of osteoprotegerin to coronary calcium and aortic plaque (from the Dallas Heart Study). Am J Cardiol 99: 513-518, 2007.

16. Kiechl S, Schett G, Wenning G, Redlich K, Oberhollenzer M, Mayr A, Santer P, Smolen J, Poewe W and Willeit J: Osteoprotegerin is a risk factor for progressive atherosclerosis and cardiovascular disease. Circulation 109: 2175-2180, 2004.

17. Koole D, Hurks R, Schoneveld A, Vink A, Golledge J, Moran CS, de Kleijn DP, van Herwaarden JA, de Vries JP, Laman JD, et al: Osteoprotegerin is associated with aneurysm diameter and proteolysis in abdominal aortic aneurysm disease. Arterioscler Thromb Vasc Biol 32: 1497-1504, 2012.

18. Schoppet M, Preissner KT and Hofbauer LC: RANK ligand and osteoprotegerin: Paracrine regulators of bone metabolism and vascular function. Arterioscler Thromb Vasc Biol 22: 549-553, 2002.

19. Collin-Osdoby P: Regulation of vascular calcification by osteoclast regulatory factors RANKL and osteoprotegerin. Circ Res 95: 1046-1057, 2004.

20. Venuraju SM, Yerramasu A, Corder R and Lahiri A Osteoprotegerin as a predictor of coronary artery disease and cardiovascular mortality and morbidity. J Am Coll Cardiol 55: 2049-2061, 2010.

21. Bennett BJ, Scatena M, Kirk EA, Rattazzi M, Varon RM, Averill M, Schwartz SM, Giachelli CM and Rosenfeld ME: Osteoprotegerin inactivation accelerates advanced atherosclerotic lesion progression and calcification in older ApoE-/- mice. Arterioscler Thromb Vasc Biol 26: 2117-2124, 2006.

22. Bucay N, Sarosi I, Dunstan CR, Morony S, Tarpley J, Capparelli C, Scully S, Tan HL, Xu W, Lacey DL, et al: Osteoprotegerin-deficient mice develop early onset osteoporosis and arterial calcification. Genes Dev 12: 1260-1268, 1998.
23. Min H, Morony S, Sarosi I, Dunstan CR, Capparelli C, Scully S, Van G, Kaufman S, Kostenuik PJ,Lacey DL, et al: Osteoprotegerin reverses osteoporosis by inhibiting endosteal osteoclasts and prevents vascular calcification by blocking a process resembling osteoclastogenesis. J Exp Med 192: 463-474, 2000.

24. Ovchinnikova O, Gylfe A, Bailey L, Nordström A, Rudling M, Jung C, Bergström S, Waldenström A, Hansson GK and Nordström P: Osteoprotegerin promotes fibrous cap formation in atherosclerotic lesions of ApoE-deficient mice-brief report. Arterioscler Thromb Vasc Biol 29: 1478-1480, 2009.

25. Candido R, Toffoli B, Corallini F, Bernardi S, Zella D, Voltan R, Grill V, Celeghini C and Fabris B: Human full-length osteoprotegerin induces the proliferation of rodent vascular smooth muscle cells both in vitro and in vivo. J Vasc Res 47: 252-261, 2010

26. Moran CS, Jose RJ, Biros E and Golledge J: Osteoprotegerin deficiency limits angiotensin II-induced aortic dilatation and rupture in the apolipoprotein E-knockout mouse. Arterioscler Thromb Vasc Biol 34: 2609-2616, 2014

27. Bumdelger B, Kokubo H, Kamata R, Fujii M, Yoshimura K, Aoki H, Orita Y, Ishida T, Ohtaki M, Nagao M, et al: Osteoprotegerin prevents development of abdominal aortic aneurysms. PLoS One 11: e0147088, 2016.

28. Morony S, Tintut Y, Zhang Z, Cattley RC, Van G, Dwyer D, Stolina M, Kostenuik PJ and Demer LL: Osteoprotegerin inhibits vascular calcification without affecting atherosclerosis in $\operatorname{ldl}(-/ /-)$ mice. Circulation 117: 411-420, 2008.

29. Mäki JM, Räsänen J, Tikkanen H, Sormunen R, Mäkikallio K, Kivirikko KI and Soininen R: Inactivation of the lysyl oxidase gene Lox leads to aortic aneurysms, cardiovascular dysfunction, and perinatal death in mice. Circulation 106: 2503-2509, 2002.

30. Callegari A, Coons ML, Ricks JL, Rosenfeld ME and Scatena M: Increased calcification in osteoprotegerin-deficient smooth muscle cells: Dependence on receptor activator of NF-kB ligand and interleukin 6. J Vasc Res 51: 118-131, 2014.

31. Olesen P, Ledet T and Rasmussen LM: Arterial osteoprotegerin: Increased amounts in diabetes and modifiable synthesis from vascular smooth muscle cells by insulin and TNF-alpha. Diabetologia 48: 561-568, 2005.

32. Zhang J, Fu M, Myles D, Zhu X, Du J, Cao X and Chen YE: PDGF induces osteoprotegerin expression in vascular smooth muscle cells by multiple signal pathways. FEBS Lett 521: 180-184, 2002.

This work is licensed under a Creative Commons Attribution-NonCommercial-NoDerivatives 4.0 International (CC BY-NC-ND 4.0) License. 